\title{
Presentación: La identidad digital como meta
}

\author{
Wileidys Artigas \\ Editora
}

TELOS se ha caracterizado por tener las puertas abiertas para todos aquellos investigadores que necesitan socializar su conocimiento, sean estos noveles o experimentados; de manera que tanto la creatividad como la experiencia nutran el desarrollo de la ciencia. Así ha ido avanzando en el reconocimiento internacional, y estando a pocos meses de ser evaluada por la Web Of Science (primer trimestre 2020), no queda más que seguir abriendo las puertas a la investigación desde cualquier parte del mundo y en idiomas como español, portugués e inglés.

Este año que finaliza se ha observado como los investigadores de todas partes luchan por obtener un posicionamiento en las redes sociales académicas, forjando su identidad digital desde las métricas tradicionales hasta las métricas alternativas, pudiendo así lograr mayor interacción y contacto con pares de origen internacional y avanzando en el desarrollo de la sociedad del conocimiento. Sin embargo, no solo los investigadores deben forjarse una identidad digital, también las revistas luchamos por hacernos un nombre y reconocimiento y aunque tengamos algunos inconvenientes en el plano nacional, seguiremos trabajando arduamente por lograrlo.

En este fin de año y al cumplir 10 años en mi rol de editora, no puedo más que agradecer toda la confianza de los autores que a través de los años han creído en nosotros y en la posibilidad de avance de la ciencia a través de la publicación de sus trabajos en la revista. Seguidamente cumplirán su rol y posicionarán los documentos en acceso abierto en las distintas redes, igual como nosotros lo haremos desde los índices y bases de datos en donde nos encontramos. Para esta ocasión contamos con trabajos de Colombia, Chile, México, Argentina, Ecuador, Perú, y por supuesto, de Venezuela. 
Estamos seguros de que poco a poco seguiremos encontrando espacios en las distintas áreas de conocimiento en función de nuestro trabajo continuo de mejora y actualización en beneficio de la comunidad científica, se enlistan a continuación: una nota al editor, 12 artículos y un documento de entrevista, en su orden de aparición y haciendo referencia al área de conocimiento en el que se inserta:

- Lamentablemente iniciamos con una Nota al Editor in Memoriam del Profesor José Padón Guillen, quien será recordado por sus grandes aportes en metodología y epistemología y la profesora Ilya Casanova hace honor a su legado.

- Tic para la educación: sistema adaptativo basado en mecanismos de aprendizaje automático para la apropiación de tecnologías en estudiantes de educación media de Andrea Otero, Wilfred Rivera, Camilo Pedraza y José Raúl Canay; que se ubica dentro de educación y esta interligado con tecnología (TIC específicamente).

- Evaluar por competencia o como potencia. Una mirada reflexiva y crítica de Josefa Zabala de Alemán y José Sánchez Carreño; también del área de educación.

- Competencias del gerente educativo en instituciones educativas de Riohacha, Colombia de Vianet Calle, siguiendo el área de educación ligado con gerencia.

- La biojurídica o el bioderecho como mediador de los nuevos dilemas biomédicos de Juan Carlos Araujo-Cuauro; quien hace un aporte desde el derecho que beneficia también a las ciencias médicas.

- Responsabilidad social en las cooperativas de ahorro y crédito del Ecuador: una medición desde la web de Andrea Fabiola Piedra Méndez, Adriana Verónica Hinojosa Cruz, María Fernanda Guevara Segarra y José Felipe Erazo Garzón; dentro del área de gerencia.

- Servicios web 2.0 en el portal UNICA de Rigo Grimaldos y Anny Paz; relacionado con ingeniería de sistemas.

- El emprendimiento social en el turismo comunitario de la provincia de Manabí, Ecuador de Carmen Auxiliadora Lucas Mantuano, Gladys Salazar Olives y Claudia Katiuska Loor Caicedo; relacionado con gerencia en el área social.

- Modelo social como alternativa para el desarrollo de la persona con discapacidad, Callao. Perú de Félix David Garay Ordoñez y Irma Milagros Carhuancho Mendoza; relacionado con gerencia en el área social.

- Estilos de aprendizaje: estrategias de enseñanza en LUZ de Engels Ortega; Ilya Casanova; Ítala Paredes y Liliana Canquiz; relacionado con educación y gerencia.

- ¿Miramos el mundo a través de la grieta? Análisis del tratamiento editorial de la cumbre intercoreana desde Argentina de Geraldina Dana, Catalina Mas, María Emilia Reiszer y Emilio Gabriel Soto; relacionado con comunicación social.

- internacionalización del currículo universitario virtual en el contexto de la globalización De Michel Valdés Montecinos, relacionado con educación. 
- Construcción participativa de modelos de negocios en organizaciones rurales de Carolina Quiñonez Zúñiga y Luz Elena Laverde Urrea; relacionado con gerencia en el área social.

- Somos todos mexicanos: uma conversa com murilo seabra Murilo Seabra e Arthur Xavier (entrevista en portugués), el cual se relaciona con investigaciones para las ciencias sociales y filosofía.

En este sentido, se observa la interrelación entre distintas áreas de saber, punto central en el logro del posicionamiento de la imagen digital, ya que para poder tener reconocimiento en las Redes Sociales Académicas se necesita tener amplitud en el desarrollo del conocimiento, poder compartir conocimiento con pares de la misma área y de áreas relacionadas. Esto significa apertura del investigador a otras visiones, que puedan no solo seguirle aportando a su área, sino también de todas las áreas que puedan interrelacionarse.

La identidad digital es un tema que estará dando mucho de que hablar en los próximos años y los investigadores tendrán que aprender a vivir con ella y a aprovechar las herramientas que puedan beneficiarlo en la búsqueda de la mejora de su trabajo para y con la sociedad. Solo nos queda desde las revistas seguir impulsado la difusión del conocimiento como parte fundamental de la imagen digital propia y colectiva. Feliz final de año 2019 y nos encontraremos de nuevo en enero con más buenas noticias, pues fin de año siempre es sinónimo de esperanza y avance. 